\title{
"En la Radio han dicho que no se Puede Tocar Nada...". Reflexiones sobre el Patrimonio Arqueológico en la Provincia de San Juan (Argentina) $)^{l}$.
}

"In the radio they have said that nothing can be touched..." Reflections about the archaeological heritage in San Juan (Argentine).

Carina Jofré y Gabriela GonZÁlez ${ }^{2}$

\section{RESUMEN}

Cuando los/as arqueólogos/as hablamos de protección, conservación y revalorización del patrimonio histórico y cultural solemos referirnos a aquellas pautas y reglamentaciones que como grupo selecto estamos autorizados a recomendar. ¿Pero qué sucede con aquellas ideas, conceptos y significados que los sujetos y comunidades no cientificas o académicas poseen acerca de su propio patrimonio histórico, arqueológico, cultural? Definir a priori las caracteristicas y significados de los bienes culturales de las sociedades ha sido siempre la politica imperante en nuestro pais, y someter esta situación a crítica debería ser una prioridad de la agenda de las investigaciones.

Consideramos que es de suma importancia conocer aquel mundo de significaciones que crean y recrean los sujetos y comunidades, como una forma de involucramiento sincero con el trabajo arqueológico que realizamos. En relación a esto, aqui nos referimos a algunos aspectos de una investigación arqueológica que actualmente se encuentra en curso en la Provincia de San Juan. Enfatizamos la

\footnotetext{
Este trabajo fue presentado con modificaciones en la "Mesa Redonda: Preservación del patrimonio arqueológico: Propuestas pedagógicas desde distintos espacios socioculturales" del XVI Congreso Nacional de Arqueología Argentina llevado a cabo en la ciudad de San Salvador de Jujuy entre el 8 al 12 de octubre de 2007. Originalmente este trabajo fue presentado con el título: "El Patrimonio Arqueológico de la Provincia de San Juan en la versión de la gente".

2 Cayana: Colectivo de Arqueología. Escuela de Arqueología, Universidad Nacional de Catamarca. Avenida Belgrano 300. Predio Universitario, Pabellón Norte. San Fernando del valle de Catamarca, Catamarca. República Argentina. E-mail: cayanacolectivodearqueologia@gmail.com
}

Recibido: Marzo 2008. Aceptado: Octubre 2008. 
relación que los agentes sociales y algunas comunidades entablan con el pasado indígena, sus elaboraciones de los usos y significados del patrimonio cultural arqueológico.

Palabras claves: Patrimonio arqueológico, Significaciones sociales, San Juan.

\section{Abstract}

When archaeologists speak about protection, conservation and revaluation about the historical and cultural heritage we usually talk about those guidelines and regulations we are authorized to recommend as a select group. What happens to those ideas, concepts and meaning that the actors and academic or scientists communities have about their own historical, archaeological cultural heritage? To define beforehand the characteristics and meaning of the cultural goods of the societies has always been the prevailing policy in our country, and to make a reflection about this situation must be taken as a priority of the investigations. We considered it is very important to know those meanings that the agents or actors and communities create and recreate, as a real way of becoming part of the archaeological work we make. In this way, we will talk about some aspects of an archaeological investigation in course in San Juan, Argentina. We want to emphasize in the relationship that the social agents and some communities make about the indigenous past, their elaborations of the uses and meanings of the archaeological heritage.

Key words: Archaeological heritage, Social meanings, San Juan.

\section{BREVE CARACTERIZACIÓN DE LAS INVESTIGACIONES ARQUEOLÓGICAS EN LA PROVINCIA DE SAN JUAN}

La meta de la ciencia decimonónica era deshistorizar al indio, negarle su identidad y cultura (Stagnaro 1993), mientras que las campañas militares se encargarían del exterminio físico de lo indígenas y la posterior ocupación de sus tierras. Dentro de este proyecto de nación en Argentina se generaron políticas culturales que recortaron, suprimieron, privilegiaron y conservaron determinados campos del patrimonio cultural. En este proceso, el Estado y algunos sectores privados fueron asumiendo el papel para definir el patrimonio cultural que correspondería a la nación argentina. 
En la provincia de San Juan, la transformación de lo indígena en objetos y sitios arqueológicos susceptibles de integrar el patrimonio arqueológico de la provincia fue un proceso iniciado por las élites locales que, de una manera u otra, fueron apropiándose física y simbólicamente de la cultura material indígena, sobreponiendo así sus interpretaciones sobre el pasado local. La historia indígena se convirtió en la Prehistoria provincial que, ubicada en un pasado lejano, se diferenció del pasado histórico provincial más cercano. La Prehistoria fue atribuida a esas "otras sociedades" que poblaron la provincia y que hoy se presumen desaparecidas. Lo indígena fue asimilado a la naturaleza -más cercana a lo salvaje y bárbaro-y separado de la "cultura provincial sanjuanina”.

La historia de las investigaciones arqueológicas en San Juan puede situarse desde el temprano trabajo de Aguiar (1900), al cual siguieron algunas breves pero conocidas publicaciones en la provincia, muchas de las cuales no tuvieron resolución de continuidad (Berberian, Calandra y Sachero, 1968; Berberian, Martin de Zurita, Gambeta, 1981; Beorchia Nigris, 1975, 1985; Castro y Castro, 1979; Debenedetti, 1917; González, 1967; Iribarren Charlin, 1952; Prieto, 1992; Sachero, 1976; Shobinguer, 1962, 1966; Vignati, 1934, entre otros). Por su parte, desde fines de 1960 se comenzó a desarrollar en la provincia una monolítica línea de investigación dirigida por Gambier y posteriormente por Micheli. Entre algunas de sus conocidas publicaciones pueden mencionarse: Gambier (1970, 1971, 1975, 1977, 1988, 1992, 1994, 1997, 2001, entre otros); Gambier y Sachero (1969, 1970); Micheli (1983, 1996, 1998, 2000, 2004); Riveros (2004); Riveros y Varela (2001). Estas investigaciones fueron desarrolladas desde el recientemente denominado "Instituto de Investigaciones Arqueológicas y Museo Prof. Mariano Gambier"3 (dependiente de la Universidad Nacional de San Juan), extendiéndose por casi toda la provincia y abarcando diferentes lugares y periodos de ocupación indígena prehispánica. Salvo algunos trabajos de Micheli, en los cuales se abordó el estudio de algunos momentos históricos de introducción española y colonia (aunque siempre con énfasis en la interacción con sociedades indígenas) (Micheli, 1983, 1996, 1998, 2000, 2004, entre otros) en la provincia no se desarrollaron otras líneas de investigación que se embarcaran en otros tipos de estudios arqueológicos como, por ejemplo, temas relacionados con la historia reciente. Es posible que esta situación tenga relación con la sedimentada percepción local de la arqueología como una disciplina solamente dedicada al estudio de sociedades indígenas de épocas prehispánicas.

3 Antiguamente, en sus comienzos, poseía la denominación de "Museo Arqueológico D. F. Sarmiento". 
Otras investigaciones arqueológicas y antropológicas se han venido desarrollado en San Juan, algunas de ellas se han afianzado más recientemente desde centros de investigaciones fuera de la provincia (Barcena, 1989, 1991-1992; Consens, 1991, 2001; Damiani, 2002; Escolar, 2003, 2007; García, 2003, 2004; Jofré et al., 2006, 2007, 2008a, 2008b; Jofré, 2008; Podestá y Rolandi, 2000, 2001; Podestá et al., 2006; entre otros).

Tal y como lo sostiene Politis $(2003,2006 a)$, en nuestra área de estudio predomina el enfoque histórico cultural caracterizado por una jerga descriptiva que organizó la cultura material indígena en un marco temporal de culturas, períodos y fases (ídem). Particularmente estas investigaciones locales se definen por un escaso desarrollo teórico acompañado de metodologías que adoptan las topologías y seriaciones cerámicas afanadas por establecer secuencias que homologan la variabilidad arqueológica en unidades estratigráficas significativas (ídem). Podemos afirmar que en el caso de San Juan hay una tendencia hacia este enfoque con una orientación ecológica, cuyas interpretaciones acerca del cambio cultural surgen en relación a modificaciones ambientales, dando prioridad a las explicaciones que hablan de adaptaciones ecológicas de los sujetos en ambientes hostiles (Jofré 2008). No obstante, esta arqueología ambiental no ha creado datos locales o microrregionales detallados tal y como lo argumenta Politis (2003, 2006a) en su caracterización de esta línea de investigación en un contexto mayor.

Un rasgo característico de estas investigaciones en San Juan es que los investigadores han coincidido en sus interpretaciones, algunas de corte nacionalista, acerca de la discontinuidad cultural y biológica entre los sujetos indígenas del pasado y las poblaciones actuales. Algunos investigadores han sido más categóricos que otros al respecto (Beorchia Nigris, 1985; Consens, 2001; Gambier, 1975, 1977, 1988, 1994, 1997; Micheli, 1983, 1996, 1998, 2000, 2004; García, 2004; Shobinguer, 1966). La alteridad indígena fue relegada al pasado, negándose su permanencia en el presente, como modo de distanciamiento del objeto de estudio creado (Gnecco, 1999). Sobre esta negación se construyó una secuencia arqueológica regional mensurable con grados de menor a mayor complejidad, compuesta por "culturas indígenas desaparecidas" (Jofré, 2008). Desde el pensamiento tipológico (Gnecco y Langebaek, 2006), aquella arqueología normativa plantó sus bases sobre la idea de una dicotomización entre pasado y presente. Con ello restringió su teoría y práctica al pasado, descartando así la posibilidad de involucrarse en las problemáticas y conflictos sociales del presente y, sobre todo, pregonando la idea de que el pasado era un tema clausurado cuyo tratamiento en el pre- 
sente sólo posee una importancia para el estudio científico como testimonio de la historia de las culturas y civilizaciones.

Algunas investigaciones han empezado a revertir este distanciamiento entre las investigaciones y las comunidades involucradas poniendo en crisis las categorías conceptuales más empleadas de la arqueología sanjuanina y evidenciando las consecuencias últimas de estos discursos arqueológicos en el presente. Así, por ejemplo, los estudios etnográficos de Escolar han demostrado que, si bien las interpretaciones científicas mencionadas tienen un impacto sociocultural profundo al generar un corte y vaciamiento histórico (Jofré et al., 2008a), algunas comunidades locales suelen emplear las mismas "monumentalizaciones arqueológicas" para reinterpretar su presente-pasado en términos de continuidad (Escolar, 2003).

Nuestras investigaciones, de las cuales intentamos dar cuenta en este artículo, pretenden desarrollar una arqueología desde una "construcción colectiva de conocimiento" (Jofre et al., 2006, 2007, 2008b). Desde comienzos del 2006 hemos venido trabajando acerca de la importancia de rastrear las representaciones sociales y sus modos locales de narración, vinculados a "lo indígena" y "lo arqueológico", con el fin de situar nuestras propias investigaciones en el marco de las problemáticas locales, tratando de generar una apropiación social positiva de las comunidades involucradas.

Vale decir que algunos trabajos de la Arqueología Social Latinoamericana plantearon ya la necesidad de una arqueología socialmente relevante y comprometida políticamente (Lumbreras, 1981; Sanoja y Vargas, 1995), marcando una ruptura con las concepciones neopositivistas de la arqueología de fines de los años 60 (Navarrete, 2004). En la actualidad, trabajos como los de Angelo (2006); Gnecco (1999); Gnecco y Langenbaek (2006); Haber (2005a, 2005b); Nastri (2004); Navarrete (2004), han enfatizado la perspectiva crítica y conciente de la situación neocolonial del contexto latinoamericano y sus consecuencias últimas en la generación y validación del conocimiento científico construido por las arqueologías locales (Politis, 2006b).

CONSECUENCIAS PRÁCTICAS DE LOS DISCURSOS ARQUEOLÓGICOS EN SAN JUAN.

El caso de los medios de difusión educativos

En este recorrido creemos encontrar entonces, la relación constitutiva y el contexto histórico-político desde el cual emerge como tal nuestra 
disciplina, y en cuyo mismo contexto podemos rastrear los modos tradicionales de establecer "propuestas pedagógicas" para la "puesta en valor del patrimonio arqueológico". Un patrimonio que se define de todos pero que, contradictoriamente, pareciera ser sólo definido por algunos pocos capacitados "para protegerlo y cuidarlo". En este sentido, un ejemplo interesante lo constituye una página de internet de Educ.ar, auspiciada por el Ministerio de Educación de la República Argentina, en la cual se puede acceder a información sobre hallazgos arqueológicos de Calingasta, Provincia de San Juan, bajo el título: "De Momias de Leyendas": Historia y Prehistoria de una región con magia ${ }^{3}$. La página está dirigida a un público en edad escolar, incitando a los lectores a comparar sus respuestas sobre la preservación y conservación del patrimonio arqueológico con aquellas provistas por profesionales arqueólogos en entrevistas que pueden descargarse de la misma página:

-Vas caminando por un valle desierto y ¡oh! de repente ves que a tus pies hay algo similar a un hueso humano. Excavas un poco y te das cuenta de que estás frente a un hallazgo arqueológico muy importante. ¿Qué harías entonces? cialista.

- ¡Ya pensaste una respuesta? Compárala con la que cuenta un espe-

- ¿Por qué pensás que se les da tanta importancia a los restos arqueológicos? ¿Para qué pensás que sirven?

- ¿Ya pensaste una respuesta? Compárala con la que cuenta un especialista.

- ¿A dónde van las momias que se encuentran en un sitio arqueológi$\operatorname{co}$ ? cialista.

- ¿Ya pensaste una respuesta? Compárala con la que cuenta un espe-

La entrevista es realizada a Mariano Gambier y Teresa Michieli, transcribimos una parte de la misma a continuación:

\section{¿Adónde se llevaron las piezas halladas?}

Todos los restos arqueológicos (tanto los que tienen valor museográfico como los que tienen solamente valor documental) se archivan y conservan en el Instituto de Investigaciones Arqueológicas y Museo de la Universidad Nacional de San Juan, como lo establece la legislación provin- 
cial de protección de bienes culturales. Algunos son expuestos en el Museo Arqueológico (dependiente del Instituto) donde la comunidad puede conocerlos.

\section{¿Cuál es la función de los museos en relación con este tipo de hallazgos?}

El Museo, cuando funciona como tal y no como un simple reservorio de cosas viejas, permite la conservación controlada de los restos, su investigación, la revisión de esta investigación cuando se descubren o inventan nuevas técnicas o procedimientos, la protección del patrimonio histórico de la comunidad y la exhibición del mismo con la información histórica que los trabajos de investigación han conseguido.

\section{¿No se descontextúan los objetos cuando se los extrae del lugar en donde los encontraron?}

Cuando los restos son extraídos por profesionales arqueólogos no se descontextualizan, ya que justamente el trabajo profesional del arqueólogo trata de preservar documentalmente el contexto. Lo contrario sucede cuando algún aficionado hace alguna recolección o excavación porque carece de la formación y conocimiento necesario.

\section{¿Qué le diría a la gente que critica el traslado de las piezas arqueo- lógicas a los museos?}

Dejar los restos en diferentes lugares sin garantía de conservación, cuidado y estudio no sólo impediría su conocimiento sino que los sometería al riesgo de destrucción en muy corto tiempo.

El mensaje transmitido es aquel que sostiene que los bienes arqueológicos, principalmente, son objetos de valor científico, en detrimento de cualquier significación que los mismos puedan adquirir en contextos de interacción social. Los arqueólogos se representan a sí mismos como "protectores del patrimonio arqueológico", son quienes posibilitan el conocimiento a la vez que poseen las herramientas conceptuales y técnicas para el "correcto" tratamiento y manipulación de los restos arqueológicos. A través de sus mecanismos discursivos de disciplinamiento (Foucault, 2002), la arqueología en San Juan ha construido e instalado en los imaginarios colectivos representaciones segmentadas de las sociedades indígenas, estableciendo los horizontes de aparición y desaparición de estos grupos sociales, relegándolos así a un pasado remoto (Jofré, 2008). Ello suma en una visión exotizada de alteridades "desaparecidas" tras la homogeneización blanca de la construc- 
ción nacional. $\mathrm{Al}$ anular los lazos que pueden construir vínculos identitarios con los sujetos y sociedades indígenas locales, a través de su cultura material arqueológica, se hace posible para la arqueología tradicional vaciar de contenido social la retórica conservacionista que promueve.

Al mismo tiempo, este corte y vaciamiento aludido toma los fundamentos del discurso civilizatorio que se erige sobre una pedagogía de tipo lineal que sostiene la idea de que el 'otro' es un recipiente vacío, al cual se debe llenar de contenido, transmitirle aquello que yo, como profesional, sé, y que por tanto él no sabe. Esta postura resulta explícita en la respuesta de los profesionales a la última pregunta de la entrevista y en artículos publicados en revistas de divulgación: "La tarea del Museo ha sido, es y será una obra civilizadora" (Gambier y Micheli, 1985: 7). Esta tarea civilizadora comprende a sujetos que "no saben lo que hacen" y por eso son siempre peligrosos agentes destructivos del patrimonio arqueológico, y pocas veces activos productores de cultura con capacidad para otorgar sentidos en el universo de las significaciones sociales a las que está sujeta la cultura material arqueológica.

\section{El caso de la legislación patrimonial provincial}

Esta retórica cientificista, que pareciera estar ampliamente reproducida en el imaginario social, es también reproducida por la legislación patrimonial provincial (Ley $\mathrm{N}^{\circ}$ 6.801) (Jofré et al., 2007), integrándose en los espacios escolares y universitarios. Así por ejemplo, la legislación provincial sobre patrimonio vigente, promulgada en 1997 y asesorada por los investigadores arqueólogos locales, se erige sobre un concepto de patrimonio cultural y natural que los concibe como elementos aislados, homogéneos temporal y espacialmente, y residuales o externos a los sujetos y a la sociedad en general. Existe en esta definición un supuesto invariante de elementos culturales y naturales puros, incontaminados y homogéneos que prevalecen inmutables a lo largo del tiempo. Se desconocen los procesos de significación sociocultural por los cuales las personas en su vida cotidiana recrean y transforman los marcos de sentido para interpretar el mundo y orientar su acción (Giddens, 1984, 1987; Geertz, 1988). Estos esencialismos también están relacionados con la llamativa ausencia en el documento de los conceptos de cultura e identidad y su reemplazo por los más frecuentes conceptos de conocimiento cientifico y desarrollo cultural.

La ley $\mathrm{N}^{\circ} 6.801$ le adjudica al Estado provincial el derecho legal sobre el patrimonio arqueológico que se encuentra en el territorio, reservándoles 
el lugar de tenedores a los sujetos que poseen en tutela los mismos, siempre y cuando estos últimos hayan declarado la posesión de dichos bienes. Es decir, la patrimonialización de la cultura material arqueológica indígena implica necesariamente su expropiación por parte del Estado, además de expresar una forma específica de conceptuar y normativizar el pasado indígena (Crespo, 2006; Endere, 2000). Esto puede apreciarse en las clasificaciones arbitrarias entre patrimonio histórico y arqueológico que posee la ley y en el establecimiento como coordenadas históricas a la instalación de la "cultura hispana” en el territorio, ratificando así la ideología hegemónica e involucrando la ausencia de cualquier cuestionamiento sobre estos eventos de exterminio físico y simbólico de los sujetos y sociedades indígenas (Crespo 2006).

La legislación provincial referida provee una clasificación patrimonial en la cual se traslucen algunas de las representaciones que el Estado provincial hace de los Pueblos Originarios (los "otros") y de la sociedad sanjuanina (el "nosotros"). En toda la declaratoria no se hace alusión alguna a los Pueblos Originarios, indígenas, aborígenes o nativos, solo se hace referencia a un colectivo provincial y regional (Provincia de San Juan y Región Cuyo) en relación a un territorio. Las alteridades y/o identidades indígenas son aludidas de forma indirecta en la ley sólo cuando se refiere "a las culturas anteriores al establecimiento de la cultura hispana en el territorio provincial". Esta negación ubica en el campo de lo "impensable" todo reclamo de devolución y/o recomposición a los sujetos y/o comunidades que adscriban a identidades aborígenes en la provincia. De hecho, las organizaciones y comunidades indígenas locales no tienen representación en el Consejo Provincial de Patrimonio Cultural y Natural creado por la ley 6.801.

En esta legislación prima la visión del patrimonio arqueológico como objetos del pasado sin vinculación con el presente, testimonio mudo de un mundo perdido. Fue esta cosificación del pasado indígena lo que lo hizo apropiable por parte del Estado en tanto "objeto" de interés y estudio de la ciencia (Crespo, 2006). A través de esta ley se establece como único criterio de valoración del patrimonio arqueológico indígena su aporte al "desarrollo cultural" de la Provincia de San Juan. En ella se sostiene que: "Todos los bienes que, conforme a lo establecido en la presente ley integran el Patrimonio Cultural y Natural de la Provincia de San Juan, deberán ser conservados como testimonio para el conocimiento y desarrollo cultural de las generaciones futuras". La inclusión del lenguaje del "desarrollo" en esta acepción del patrimonio cultural -en el cual se encuentra contenido el patrimonio arqueológico-supone la adhesión a un proyecto político de transformación 
cultural basado en las experiencias de la modernidad capitalista (Escobar, 1991, 2001).

\section{El caso de los espacios escolares en la provincia}

Por otra parte, en el ámbito educativo, tras dos años de trabajos de investigación, pudimos constatar sorpresivamente que en las escuelas rurales del Norte de la provincia, los docentes trabajan con material bibliográfico producido por las investigaciones arqueológicas sin previa adaptación para su transposición didáctica o contenidos acordes a las demandas educativas en el nivel inicial y medio en contextos rurales. Los textos mayormente empleados son Gambier (1977, 1988, 2000) y Micheli (1983). En casi todos los casos, la transposición didáctica se hace sin una valoración crítica de los contenidos impartidos en los diferentes contextos de enseñanza, arrastrando categorías problemáticas (como aquellas señaladas en las secciones anteriores) a la hora de abordar la historia local.

Algunos docentes rurales señalan la ausencia de material bibliográfico que narre la historia local, dado que el material arqueológico e historiográfico a disposición sostiene la extinción aborigen tras la irrupción española, dejando planteada solamente la construcción de una modernidad occidental blanca. De esta manera los maestros se ven obligados a impartir bibliografía referente a poblaciones indígenas actuales de otras regiones de la Argentina, abonando con ello la construcción de un presente aborigen externo y lejano. Esto mismo pudo constatarse en talleres realizados con alumnos de diferentes edades en comunidades como Malimán, Angualasto y Colanguil (Departamento de Iglesia) y Pachimoco (Departamento de Jáchal). En menor medida algunos docentes emplean manuales escolares recomendados por el currículo, sin embargo, en estos casos la situación no es muy distinta, ya que la gran mayoría de dichos textos reproducen historias de aborígenes de los "grandes centros de cultura" como Perú y Mesoamérica, sin referencia alguna a la historia aborigen local.

Los talleres y jornadas llevados a cabo con docentes rurales en el Norte de San Juan pusieron de manifiesto concepciones de la historia como algo lejano, cuya utilidad "rescata" la arqueología para el "conocimiento" del pasado de los "primitivos habitantes". En cuanto a la categorización de la arqueología como disciplina, los maestros la vincularon con el estudio del pasado a través de restos materiales de grupos indígenas. En relación a esto último, una visión que, tal como hemos mencionado antes, puede ser rastreada en la bibliografía especializada local, los docentes también identifican 
"lo indígena" como sujetos que vivieron en el pasado, es decir, que ya no están, sin contemplar la presencia de identidades indígenas presentes en la región. Esto se vincula directamente a la concepción de cultura e identidad como elementos estáticos inmutables en el tiempo.

Finalmente, al abordar la categoría de Patrimonio Cultural Arqueológico, algunas maestras se remitieron a la idea de que ello solamente integra "cosas materiales", como restos de elementos indígenas que sirven de testimonio de un pasado remoto y extraño.

\section{El caso de los museos públicos y privados con colecciones arqueológicas}

La idea de la desaparición física de los sujetos y sociedades indígenas es constitutiva de la historia provincial y nacional, y ha permitido, entre otras cosas, concebir a los museos de la provincia de San Juan como repositorios; el almacén de los objetos que pertenecen al pasado remoto, que no son de nadie y son a la vez de todos.

Los museos con colecciones arqueológicas, ya sean privados o provinciales, de la zona capitalina y del interior de la provincia reproducen la concepción de lo indígena como parte de la naturaleza. Las salas dedicadas a la arqueología, donde ésta es identificada con lo indígena exclusivamente, se componen de una acumulación de objetos que se presentan como restos materiales dejados por los "indios", sin una incorporación de los sujetos históricos que los produjeron. Es común que en las muestras museográficas se advierta una relación muy estrecha entre las épocas de ocupación indígena del territorio con las tempranas etapas geológicas de la evolución de la tierra representada, generalmente, por objetos tales como fósiles y rocas minerales. Esto se corresponde con aquella narrativa hegemónica sobre el estado de naturaleza de los pueblos originarios, por oposición al "nosotros" nacional/ provincial "civilizado"; retórica central del Estado provincial apoyado en los preceptos sarmientinos naturalizados como esencia de la "identidad sanjuanina”.

Llama la atención que el concepto de Patrimonio Arqueológico no aparece como elemento de los mensajes de la cartelería, audios o en las palabras de los guías que acompañan las recorridas museográficas de estos museos de la provincia. Cuando se habla de patrimonio se lo hace en referencia al Patrimonio Cultural integrado por los objetos y las tradiciones tecnológicas o costumbres de "lo puramente sanjuanino", esto es, las manifestaciones del pasado colonial hispano y provincial-republicano. A su vez, este "patrimonio sanjuanino" representa sólo a un sector de la sociedad: a las clases 
sociales dominantes locales que desde mediados del siglo XIX perseguían un proyecto de Estado-Provincial equivalente al Estado-Nación Argentino. En este sentido vale decir que, particularmente en San Juan, se apuntalaron históricamente dos premisas básicas, dos principios de inclusión-exclusión para la incorporación de la población, territorio y economía de su territorio: considerar a la provincia "libre" de población indígena y borrar la vinculación con Chile exaltando la participación de los sanjuaninos en la soberanía argentina (Escolar, 2001).

También en las reelaboraciones que realizan los museos de la provincia de San Juan están presentes todos lo elementos conceptuales con los cuales se caracteriza al Patrimonio Arqueológico provincial en la ley $\mathrm{N}^{\circ} 6.801$, que como hemos mencionado tiene estrecha relación con las representaciones del pasado indígena local provistas por los arqueólogos.

Los museos arqueológicos de la provincia, autodenominados repositorios legales del Patrimonio Arqueológico local, también hacen uso de conceptos de cultura e identidad que resultan problemáticos en su abordaje social del Patrimonio Arqueológico y Cultural en general. La cultura es concebida como localizada y homogénea, como elemento residual o externo a los sujetos y posible de ser definida a partir de rasgos estáticos homogéneos e identificatorios de un "ser sanjuanino" ideal. Se afirma que los museos irradian cultura, porque la cultura está en el museo. Se confunde cultura con un conjunto de objetos estáticos que por su sola cualidad de antiguos transmiten saber. De ahí que se conciba a estos espacios como lugares en donde se acumula conocimiento. ¿Qué ocurre con aquellos que no visitan el museo?

Por último, las clasificaciones confusas de patrimonio cultural, histórico, arqueológico, etnológico, natural, provista en la legislación se trasladan también al discurso de los museos. Las palabras claves de "modernización" y "desarrollo", junto a "conocimiento científico", aparecen conjugadas en el discurso de los museos en un sentido similar al de la legislación provincial.

\section{UNA ETNOGRAFÍA PARA LA CONSTRUCCIÓN COLECTIVA DE UNA ARQUEOLOGÍA DISTINTA}

Luego de más de un año y medio de trabajo en la provincia de San Juan indagando sobre las narrativas y relatos locales del pasado indígena, nos encontramos frente a la posibilidad de poder articular estas reflexiones con 
los sentidos que emanan de los sujetos con los que fuimos construyendo esta nueva mirada de la arqueología, o por lo menos de aquella arqueología que queríamos hacer a través de una construcción colectiva.

La gente de las áreas rurales y urbanas de la provincia: pobladores, maestros, alumnos, guías y directivos de museos, oficiales gendarmes, agentes municipales y del Estado provincial, arqueólogos y coleccionistas, todos ellos nos fueron dando pistas sobre sus puntos de vistas siempre diferentes y diferenciales. De esta forma, luego del trabajo de campo, que implicó una metodología de tipo etnográfico con empleo de observaciones, entrevistas, relevamientos de documentos, seguidos de charlas, talleres y jornadas en espacios educativos, museos y universidad, nos encontramos con una escisión entre lo que para nosotros constituía, desde el saber científico, un 'bien patrimonial' o arqueológico, y lo que para nuestros interlocutores era una construcción histórica de sentido atravesada por su lugar específico en el mundo.

Nuestra propuesta para la conservación y preservación del patrimonio arqueológico, es en sí misma una provocación crítica a estos mismos conceptos empleados por la arqueología y, al mismo tiempo, se inscribe en una pedagogía que parte fundamentalmente del reconocimiento de que cada sujeto es portador de un saber, y concepciones del mundo y, por tanto, cada uno puede aportar a la construcción de conocimiento (Freire, 2003a, 2003b; Neufeld, 1999). En congruencia con esto, la metodología de trabajo optada se articula en una investigación que indaga acerca de los conocimientos locales del pasado-presente indígena desde la propia construcción de sentido de los sujetos devenidos en interlocutores válidos. Estos últimos, a través de sus experiencias tematizan al "patrimonio arqueológico" inscribiéndose en matrices discursivas que poseen su propia historia y desde donde también otras voces hablan y dicen a través de ellos, tejiendo así complejas tramas de interacción social vinculadas a diversos planos y registros de la vida de los sujetos.

La noción de diálogo resulta fundamental en nuestra teoría y práctica arqueológica, puesto que hablar de diálogo habilita a que dentro del proceso de investigación puedan articularse distintos saberes en la construcción de conocimiento y es a partir de esta articulación desde donde puede emerger la posibilidad de la construcción teórica de un objeto de estudio arqueológico. Partir desde lo dialógico, implica adherir a una concepción determinada de sujeto, dado que el diálogo sólo es posible desde la relación sujeto-sujeto y no de la de sujeto-objeto. Esta relación parte la idea de que todo sujeto 
es portador de una historia con sentido y toda historia con sentido es importante de ser conocida (Piña, 1986). Sin embargo, estos supuestos no se encuentran restringidos a la sola experiencia del sujeto investigador, sino que son parte de una relación dialéctica por la cual, tanto el investigador como el sujeto de la problemática se constituyen mutuamente. De esta forma, son los distintos saberes en tensión los que dan lugar a la producción colectiva de conocimiento durante todo proceso de investigación. Cuando hablamos de producción colectiva nos referimos entonces, a una forma distinta de pensar al 'otro' y, por ende, a todo trabajo de investigación.

De esta forma, se abre la posibilidad de una historización del "yo" con el "otro", que al revivir las experiencias de cada uno permite hacer pensar al "otro" y, al mismo tiempo, el "otro" me hace pensarme a "mí mismo" (Bianchi y Silvano, 2001). Por otro lado, toda interpelación de "uno" frente a ese "otro", requiere siempre que ambos se posicionen, implícita o explícitamente, con el fin de reconocer la igualdad en la diferencia (ídem). Así, al pensar a partir desde una relación dialógica, poco a poco se va dando lugar a nuevas formas de interpretar y abordar tanto el presente como el pasado que lo constituye.

El patrimonio arqueológico bajo el prisma de las significaciones sociales. El caso de Malimán.

¿Acaso el propio término de patrimonio no encierra aquella misma práctica a la cual buscamos oponernos? ¿Es posible articular los diversos saberes (el de los sujetos de las comunidades y los nuestros -investigadores-) aun cuando hasta el lenguaje que empleamos resulta ya distante y anacrónico? Una manera de dar respuesta a estas preguntas es a partir de lo que los mismos pobladores de Malimán nos contaron durante una entrevista:

Poblador -Por la radio han dicho que no se puede tocar nada...

Carina Jofré -Y ustedes qué piensan de eso?

CJ -Digamos, eso es lo que dicen en la radio, ¿pero qué piensan de eso?

P -Si lo piden en nombre de la ciencia... pongamos acá, ese pedacito de tierra nos dicen lo que hacen... si van a venir y no van a hacer nada, o van a dejar eso así no más, o lo van a destruir... (...) que vengan como turismo, a ver, bueno, está bien... porque capaz que ustedes como turismo, qué sé yo, 
pueden comprar algo, pueden dejar algo... pero si van a venir a romperlo o a llevárselo, no...

Gabriela González - ¿Y acá ha pasado eso, han venido los arqueólogos $\mathrm{u}$ otra gente a llevarse las cosas arqueológicas?

P -No... no, porque aquí no hay gran cosa como en otros lugares de la zona (....) que yo, que haya visto que haya pasado, no.

GG - ¿Y usted sabe de algún lugar en el que haya cosas?

P -¿Cayanitas? Les llamamos así nosotros...

CJ - ¿Cayanitas?

P -Claro, cayanas... de los cántaros... nosotros todos los días vemos cayanas.

CJ - ¿Y la abuela María tiene memorias de esto?

P -No, no, no... ella, no... nunca nos ha comentado de historias...

$\mathrm{CJ}-\mathrm{¿}_{\mathrm{O}}$ nunca le preguntaron?

P -Bueno, ahí está el tema... nosotros no le damos importancia. Pero si viniese un contacto del gobierno, llevan esto ustedes (señala un objeto) y cobran por él, ahí sí le vamos a dar importancia (...) Cobren por ahí \$2 por ver el lugar (se refiere a los sitios arqueológicos). Si usted va a entrar y va a sacar... pero, cobrándole, sí...

A través de esta entrevista realizada en noviembre de 2006 a una familia de Malimán, un pequeño poblado de 40 habitantes en el Distrito Angualasto, al norte del Departamento Iglesia, pudimos comprender que las "cayanitas", lo que para nosotros son fragmentos de cerámica indígena de épocas pasadas, al estar inscriptas en el mundo de lo cotidiano forman parte de las experiencias vivibles de los sujetos. Y si bien, las cayanitas también son referentes arqueológicos, es decir, son buscadas por los/as arqueólogos/ as, no están estrictamente patrimonializadas, como sí lo están los objetos considerados de "valor patrimonial": los objetos arqueológicos completos, los cuerpos momificados, los sitios arqueológicos, etc. Mientras que las cayanitas parecen inscribirse en el mundo de lo cotidiano, lo arqueológico se constituye a partir de su apropiación y expropiación por parte de la ciencia para el Estado, en tanto bien que adquiere un valor científico, según lo enuncian las investigaciones y la legislación patrimonial. 
En la entrevista citada, el poblador sostiene que ellos no le dan interés, es decir, las "cayanas" forman parte constitutiva de sus experiencias cotidianas en el lugar, y en tal sentido no son objetivadas estrictamente como objetos de valor científico y/o de mercado. El mismo señala que esa objetivación es externa a ellos y, si bien no la problematiza demasiado, la apropia y la adapta a su realidad de subalternidad, subvirtiendo de este modo el propio sentido hegemónico implicado en el estado de patrimonialización de "lo arqueológico". En la versión de la cayana, el poblador de Malimán sostiene que debería instruírselos sobre el valor patrimonial de los restos arqueológicos para, de esta forma, sacar algún tipo de beneficio -en este caso económico- para la comunidad.

Es interesante que el entrevistado se refiera a "contactos del gobierno" para aludir a los especialistas que pueden reconocer el valor de estos objetos del pasado. Esta es una percepción que, lejos de estar errada, nos advierte sobre la mirada de los pobladores locales sobre la relación cómplice de los arqueólogos/as con las políticas de intervención del Estado.

Al preguntar por "lo arqueológico" los lugareños hacen alusión a aquellos objetos y lugares que son objetivados como arqueológicos por "los que saben" y que, en tal sentido, no pueden tocarse y están prohibidos. Pero también se advierte una apropiación de la lógica moderna desarrollista, abiertamente promocionada en el lugar por los arqueólogos a través de la Universidad Nacional de San Juan, los organismos de incumbencia patrimonial del Estado provincial, Administración del Parque Nacional San Guillermo, el Municipio, y por la Empresa Minera Transnacional Barrick. Los pobladores sostienen que el patrimonio arqueológico local debe servir para generar alternativas económicas para el desarrollo de las comunidades, tal como también se espera que lo hagan la administración de los recursos naturales del Parque Nacional y las explotaciones metalíferas que actualmente realizan los capitales extranjeros en la región.

En esta valorización de lo propio, que se presenta a primera vista como una cuestión de índole económica, se subsumen sentidos de pertenencia relacionados con los procesos de construcción de las identidades locales, enfrentadas o diferenciadas de otras regiones. Es así que los sentidos acerca del pasado muchas veces son utilizados para negociar espacios sociales (Escolar, 2003, 2007; Gordillo, 2006; Isla, 2002). Esta significación de la "cayana" inscripta en el mundo de "lo cotidiano" y en oposición a "lo arqueológico", puede ser interpretada como una apropiación que intenta subvertir las relaciones hegemónicas de poder que atraviesan la esfera cultu- 
ral y económica local. Dicho de otro modo, los discursos de los pobladores de Malimán se montan sobre las propias hegemonías y al hacerlo le dan un sentido local a las políticas desarrollistas (Escobar, 2001) involucradas en las significaciones del patrimonio arqueológico en San Juan. No se trata de una simple reproducción de estos discursos hegemónicos, dado que las significaciones locales de "lo arqueológico" son reorientadas esta vez de acuerdo a los intereses sociopolíticos de las comunidades en cuestión, apartándose de los intereses manifiestos de los grupos y sectores de poder. De esta forma, los pobladores de Malimán, representan el patrimonio arqueológico local con sentidos propios anclados en su experiencia con el mundo, distanciándose y generando alternativas al estado de "patrimonialización" (expropiación cultural) al que son expuestos.

\section{A MODO DE CONCLUSIONES}

A partir del ejemplo proporcionado con el caso de Malimán, y en el marco de la caracterización que hemos realizado de la arqueología sanjuanina y sus repercusiones en ámbitos públicos, sostenemos que es posible trazar una relación entre la construcción del patrimonio cultural-arqueológico sanjuanino y una epistemología moderna-desarrollista. Para entender esto es necesario situar al patrimonio cultural-arqueológico indígena como parte de una construcción histórica atravesada por relaciones de poder estructuradas y estructuradoras de los espacios y sujetos sociales (Giddens, 1987), estos últimos, en tanto agentes actuantes con subjetividades históricamente constituidas.

Durante sus fases de consolidación, el proceso de reordenamiento económico nacional sentó sus bases ideológicas en la des-historización y despolitización de los procesos sociales que subyacen a la pobreza, para el ocultamiento de las relaciones y estructuras de poder y los vínculos estructurales de subordinación y expropiación que ligan a los sectores populares con el conjunto social de la provincia y la nación (Machado Aráoz, 2007). Esto último alimentó un imaginario que naturalizó la pobreza como una condición ahistórica, fruto de formas económicas atrasadas, distintas y exteriores a la economía oficial del orden capitalista (ídem). El ocultamiento del poder en las políticas del desarrollo también se expresó obsecuentemente en la formulación de una ciencia pretendidamente "pura", deshistorizada y deshistorizante, coherente con la particular comprensión de la economía como un dominio separado, gobernado por leyes naturales y universales (ídem). Particularmente, en nuestro caso de estudio, esto queda claro en el 
enfoque científico desarrollista optado en la declaración patrimonial sanjuanina. Allí, con la incorporación de la noción de "patrimonio científico" dentro de la clasificación de bienes patrimoniales que ofrece la ley, queda mayormente expuesta la invocación a un discurso científico-técnico neutral, necesario para mejorar las condiciones de viabilidad del paquete cultural para el mercado (por ejemplo, por su posible rentabilidad turística y/o competencia académico-científica).

En un esfuerzo del Estado por eliminar o domesticar los fantasmas de la alteridad (Escobar, 1991, 2001), "lo arqueológico" es aludido por su importancia científica (en tanto conocimiento instrumental) para el desarrollo cultural (modernización con bases económicas), y no así por su valor como fuente de significación en los procesos de construcción de identidades locales particulares y diferenciadas. Por ello sostenemos que, la "patrimonialización de la cultura material arqueológica" en San Juan no ha implicado la valoración positiva de los Pueblos Originarios en el pasado y en el presente, por el contrario, apoyada sobre la retórica de su extinción ha servido para perpetuar la relación de hegemonía/subordinación en la cual ha sido pensada. En este escenario, la arqueología local no ha tenido capacidad para defender la diferencia cultural, y si bien siempre se ha mantenido de manera pretendidamente neutral en los embates contra las identidades indígenas, sus representaciones sobre el patrimonio arqueológico han alimentado los preceptos modernizantes del desarrollo en tanto principio central necesario como organizador de la vida social de las áreas rurales en la provincia.

De manera conjunta, los arqueólogos profesionales, los museos privados y los organismos de administración y control del patrimonio arqueológico en San Juan, en líneas generales, coincidieron en no reconocer otros discursos que involucren ideas y sentidos diferentes acerca de lo arqueológico, lo indígena, y lo patrimonial. Todo esto ha tenido y tiene un impacto profundo sobre las interpretaciones del patrimonio arqueológico indígena. Los discursos y relatos registrados en las escuelas rurales, los museos y en algunos espacios mediáticos educativos demuestran claramente que, en general, las políticas culturales impartidas en la Provincia de San Juan, y de las cuales también participa la arqueología, suelen partir de un sujeto vacío de significados, tabla raza sobre la que se escribe el progreso. Esto hace posible la reproducción eficaz de retóricas nacionalistas -adoptadas por la provincia- que combaten la diferencia cultural incorporando construcciones discursivas de la arqueología en un proceso de estructuración recursivo. 
Fue por medio de la palabra que pudimos ver, y luego reflexionar, acerca del lugar de nuestra práctica. Lugar caracterizado, la más de las veces, por la imposición de reglas y pautas avaladas por un "saber" devenido hegemónico: el científico o académico. El mismo que por radio establece prohibiciones de "no tocar el patrimonio arqueológico" - tal cual nos contaban los pobladores de Malimán, por ejemplo-, es decir, aquellos bienes culturales que por medio de la prohibición se transforman en entidades ajenas a los sujetos, sin posibilidad de formar parte de los procesos de construcción de identidades locales. Por nuestra parte, estamos convencidas de que al redefinir esta relación antagónica de conocimientos, la arqueología puede, desde otro lugar, contribuir a que a los sujetos puedan asumirse en la historia, para su activa participación en los procesos locales de reconstrucción e invención cultural.

Por todo lo dicho, al preguntarnos por nuestras propias prácticas discursivas, no pretendemos reducir el presente trabajo a un análisis del lenguaje que como investigadoras empleamos, sino que en dicho preguntarse creemos poder dar con las representaciones y significaciones que poseemos $\mathrm{y}$ construimos en nuestras interpretaciones presentes del pasado. $\mathrm{Y}$ es esa reflexión (no la imposición unilineal de saberes) la que habilita a una construcción de conocimiento y es capaz de articularse con los conceptos, ideas y significados que los sujetos poseen acerca de su propio patrimonio histórico, cultural y arqueológico. Nos posicionamos desde un paradigma dialécticocrítico, partiendo del reconocimiento de la igualdad en la diferencia de sujetos históricos en diálogo. Diálogo que habilita el encuentro con el otro por medio de la palabra dicha y sentida; diálogo en el cual, y a partir del cual los sujetos que lo van construyendo se constituyen mutuamente desde las experiencias de vida particulares de cada uno, sus saberes, valorizaciones y significaciones (Freire, 2003b).

Agradecimientos: El presente trabajo fue preparado a partir de investigaciones realizadas en el marco de proyectos en marcha desarrollados desde la Escuela de Arqueología de la Universidad Nacional de Catamarca y dirigidos por la Lic. Ivana Carina Jofré. PFIP 2006-2008, acreditado y financiado por la Secretaría de Ciencia y Tecnología e Innovación Productiva del Ministerio de Educación, Ciencia y Tecnología de la Nación. Convenio 099/ Exp. S.C.T.I.P. 0839/05. PID EDA25995603, 2006-2010, acreditado y financiado por la Secretaría de Ciencia y Tecnología de la Universidad Nacional de Catamarca. Res. C.S. Nº 012/05 Exp. 2177/05. Res. Rectoral $\mathrm{N}^{\circ}$ 0602/05. Exp. 02054/05. 


\section{BibliografíA}

Aguiar, D. 1900. Los Huarpes. Primera Reunión del Congreso Cientifico Latinoamericano, Vol.: 283-298, Buenos Aires.

Angelo, D. 2006. "La arqueología en Bolivia. Reflexiones sobre la disciplina a inicios del siglo XXI". Arqueología Sudamericana 1 (2): 185-211.

Barcena, J. 1989. "La arqueología prehistórica del Centro-Oeste argentino (Primera parte)". Xama 2: 9:60.

Barcena, J. 1991-1992. "Datos e interpretación del registro documental sobre la dominación incaica en Cuyo". Xama 4 (5): 11-49.

Beorchia Nigris, A. 1975. "La arqueología de alta montaña en la provincia de San Juan y su relación con los yacimientos de altura de la cordillera de los Andes". Centro de Investigaciones de Alta Montaña 1: 48.

Beorchia Nigris, A. 1985. El enigma de los Santuarios de Altura de alta montaña. Revista del C.I.A.D.A.M. Tomo 5. San Juan.

Berberián, E.; H. Calandra y P. Sachero. 1968. "Primeras secuencias estratigráficas para San Juan (República Argentina). La Cueva "El Peńoncito" (Dpto. Jáchal)". Actas y Memorias del XXXVII Congreso Internacional de Americanistas, vol. III: 355-369. Mar del Plata.

Berberian, E.; J. Martín de Zurita, y J. Gambeta. 1981. "Investigaciones arqueológicas en el yacimiento incaico de Tocota (Provincia de San Juan, República Argentina)". Anales de Arqueología y Etnología XXXII-XXXIII: 173-218.

Bianchi, S. y C. Silvano. 2001. "El oficio del cientista hoy... desde lo siniestro a lo ético político". Revista de la Escuela de Antropología IV: 23-28.

Castro, R. y J. Castro. 1979. Libro Celeste (The Light Blue Book). Exploración, Investigación y Exposición: Filosofía, Literatura, Teoria Excéntrica, Arqueología, Paleontología, Mecánica Excéntrica, Ovnilogía. Litografía Chales. Mendoza.

Consens, M. 1991. "Arte rupestre del valle del río San Juan (Segundo Informe)". Shincal 3 (3): 114-125.

Consens, M. 2001. "San Juan y su arte rupestre: acotaciones críticas a intentos de sistematización”. Actas del XIII Congreso Nacional de Arqueología Argentina tomo 3: 185-200. Córdoba. 
Crespo, C. 2006. Continuidades y discontinuidades en la legislación rionegrina del patrimonio arqueológico. Relaciones de la Sociedad Argentina de Antropología XXX: 297-302.

Damiani, O. 2002. "Sistemas de riesgo prehispánico en el valle de Iglesia, San Juan, Argentina. Multequina, Latin American Journal of Natural Resources 11: 01-38.

Debenedetti, S. 1917. "Investigaciones arqueológicas en los valles preandinos de la Provincia de San Juan”. Revista de la Universidad de Buenos Aires. Publicaciones de la Sección Antropológica N¹5.T. XXXII y XXXIV.

Endere, M. L. 2000. Arqueología y legislación en la Argentina. Cómo proteger el Patrimonio Arqueológico. Serie Museográfica. Volumen 1. INCUAPA. UNC. Olavarría.

Escobar, A. 1991. "Anthropology and the Development Encounter: The Making and Marketing of Development Anthropology". American Ethnologist 18(4): 658-682.

Escobar, A. 2001. Antropología y Desarrollo. En: http://www.unesco.org/issj/ rics154/escobarspa.html.

Escolar, D. 2001. "Subjetividad y estatalidad: usos del pasado y pertenencias indígenas en Calingasta”. En: Cruzando la Cordillera... La frontera ArgentinoChilena como espacio social, editado por Susana Bandieri, pp: 141-166. Publicaciones del CEHIR, Universidad Nacional del Comahue. Neuquén.

Escolar, D. 2003. "Arqueólogos y Brujos: La disputa por la imaginación histórica en la etnogénesis huarpe". Relaciones de la Sociedad de Antropología XXVIII: $23-43$.

Escolar, D. 2007. Los dones étnicos de la nación. Identidades huarpe y modos de producción de soberania en Argentina. Prometeo, Buenos Aires.

Foucault, M. 2002 Vigilar y castigar. Nacimiento de la prisión. Siglo XXI editores Argentina, Buenos Aires.

Freire, P. 2003a. Pedagogía del Oprimido. Siglo XXI editores, Buenos Aires.

Freire, P. 2003b. Pedagogía de la autonomía. Siglo XXI editores, Buenos Aires.

Gambier, M. 1971 "Primitivo poblamiento agrícola prehispánico del valle de Iglesia”. Revista del Club Andino Mercedario 6: 30-32.

Gambier, M. 1970. "Primeras conclusiones de las investigaciones en Los Morrillos y zonas aledañas". Revista del Club Andino Mercedario 5: 17-20. 
Gambier, M. 1975. "Arqueología de la región occidental de Cuyo y sus relaciones con el noroeste argentino". Publicaciones 1: 1-6.

Gambier, M. 1977. La cultura de Ansilta. Instituto de Investigaciones Arqueológicas y Museo. Facultad de Filosofía, Humanidades y Artes, Universidad Nacional de San Juan, San Juan.

Gambier, M. 1988. La fase cultural Punta del Barro. Instituto de Investigaciones Arqueológicas y Museo, Facultad de Filosofía, Humanidades y Artes, Universidad Nacional de San Juan, San Juan.

Gambier, M. 1992. Secuencia cultural agropecuaria prehispánica en los valles preandinos de San Juan. Instituto de Investigaciones Arqueológicas y Museo. Universidad Nacional de San Juan. Publicaciones 18.

Gambier, M. 1994. "La cultura de la Aguada en San Juan”. Revista Ansilta de Arqueología y Humanidades 7: 14-19.

Gambier, M. 1997. "La expansión de la cultura de la Aguada en San Juan”. Shincal 6: $173-192$.

Gambier, M. 2001. "La cultura de la Aguada en San Juan: Las manifestaciones agropastoriles anteriores al 1000 d.C.". Actas del XII Congreso Nacional de Arqueología Argentina, tomo I: 95-100. Córdoba.

Gambier, M. 2000 [1993]. Prehistoria de San Juan. $2^{\circ}$ Edición. Ansilta Editora, San Juan.

Gambier, M. y C. T. Micheli. 1985. "La investigación arqueológica y la difusión museográfica de sus resultados para la formación de la conciencia histórica de la comunidad". Publicaciones 14: 1-7.

Gambier, M. y P. Sachero. 1969. "Excavaciones en los Morillos de Ansilta”. Actas del $V^{\circ}$ Congreso Nacional de Arqueología Chilena, pp: 389-395, La Serena.

Gambier, M. y P. Sachero. 1970. "Secuencias culturales y cronologías para el SO de la provincia de San Juan, Rep. Argentina”. Hunuc Huar 1: 1-69.

García, A. 2003. Los primeros pobladores de los Andes Centrales Argentinos. Una mirada a los estudios sobre cazadores-recolectores tempranos de San Juan y Mendoza. ZETA Editores, Mendoza.

García, A. 2004. Tras las huellas de la identidad huarpe. Un aporte desde la Arqueología, la Antropología y la Historia. Centro Interdisciplinario de Estudios Regionales, Facultad de Filosofía y Letras de la Universidad de Cuyo, Serie Libros, $\mathrm{N}^{\circ} 7$, Mendoza.

Geertz, C. 1988. La interpretación de las culturas. Gedisa, Barcelona. 
Giddens, A. 1984. The Construction of Society. Outline of the Theory of Structuration. University of California Press. Berkeley, Los Angeles.

Giddens, A. 1987. Las nuevas reglas del método sociológico. Critica positivista de las sociologias interpretativas. Amorrourtu editores, Buenos Aires.

Gnecco, C. 1999. Multivocalidad histórica. Hacia una cartografía postcolonial de la arqueología. Universidad de los Andes, Bogotá.

Gnecco, C. y C. H. Langebaek (Editores). 2006. Contra la tiranía tipológica en Arqueología. Una visión desde Sudamérica. UNIANDES - CESO, Colombia.

González, A. R. 1967. "Una excepcional pieza de mosaico del NO argentino. Consideraciones sobre el fechado de C14 y la secuencia arqueológica de la Provincia de San Juan”. Etnia 6: 3-12.

Gordillo, G. 2006. En el Gran Chaco. Antropologias e historias. Prometeo Libros, Buenos Aires.

Haber, A. 2005a (Editor). Hacia una arqueología de las arqueologías sudamericanas. UNIANDES, Bogotá.

Haber, A. 2005b. "Arqueología de la naturaleza, naturaleza de la arqueología". En: Hacia una arqueología de las arqueologías sudamericanas, editado por Alejandro Haber, pp: 15-31, UNIANDES, Bogotá.

Iribarren, J. 1952. “Apuntes sobre la arqueología de la provincia de San Juan”. Publicaciones del Museo de La Serena. Boletín 6: 8-15.

Isla, A. 2002. Los usos politicos de la identidad. Indigenismo y Estado. Editorial de las Ciencias. Buenos Aires.

Jofré, C. 2008. "Arqueología de las sociedades capayanas del Norte de la Provincia de San Juan (República Argentina)". Arqueología Sudamericana 4(2): 146-1680.

Jofré, C., S. Biasatti, G. Compaña y G. González. 2006. "Saltar dela cuadrícula de excavación: un ejercicio para arqueólogos de todas las edades". En: $I V$ Jornadas Homenaje a Guillermo Magrassi. Versión digital (CD). INAPL, Buenos Aires.

Jofré, C.; S. Biasatti; G. Compañy; G. González; M. S. Galimberti, N. Najle y P. Aroca. 2007. "La Cayana: entre lo arqueológico y lo cotidiano. Tensiones y resistencias en el Norte de San Juan”. En: Libro de resúmenes de la IV Reunión de Teoría Arqueológica en América Del Sur (4TAAS), pp: 123. Catamarca. 
Jofré, C., S. Biasatti, G. González, M. S. Galimberti y P. Aroca. 2008a. "Patrimonio arqueológico al servicio del corte y vaciamiento histórico en la provincia de San Juan”. Diariolibre.info, edición 3 de febrero de 2008.

Jofré, C., S. Biasatti, G. González, M. S. Galimberti y P. Aroca. 2008b. "Are sherds in archaeology or in life?". En: Libro de resúmenes del 6to. Congreso Mundial de Arqueología, pp. 234. Dublín.

Lumbreras, L. 1981. La arqueología como ciencia social. Peisa, Lima.

Machado Aráoz, H. 2007. Economía Politica del Clientelismo. Democracia y Capitalismo en los márgenes. Encuentro Grupo Editor, Córdoba.

Micheli, C. T. 1983. Los Huarpes protohistóricos. Instituto de Investigaciones Arqueológicas y Museo Universidad Nacional de San Juan, San Juan.

Micheli, C. T. 1996. “Capayanes y Yacampis de San Juan”. Revista Ansilta 5: 3435.

Micheli, C. T. 1998. "Aproximaciones a la identidad de una cerámica indígena post-hispánica del sur de San Juan”. Publicaciones 22 (nueva serie): 55-76.

Micheli, C. T. 2000. "La disolución de la categoría jurídico-social de "indio" en el siglo XVIII: el caso de San Juan (región de Cuyo)". Publicaciones 23 (nueva serie): 1-135.

Micheli, C. T. 2004. La fundación de villas en San Juan (siglo XVIII). Sociedad Argentina de Antropología, Buenos Aires.

Nastri, J. 2004. "La arqueología argentina y la primacía del objeto". En: Teoría Arqueológica en América del Sur, editado por Gustavo Politis y Roberto D. Peretti, pp. 213-234. Ed Huemul, INCUAPA, Buenos Aires.

Neufeld, M. R. 1999. “Introducción”. En: “De eso no se habla...”. Los usos de la diversidad sociocultural en la escuela, compilado por María Rosa NeufeldJens Ariel Tristed, pp. 7-21. Eudeba, Buenos Aires.

Navarrete, R. 2004. El pasado con intención. Hacia una reconstrucción crítica del pensamiento arqueológico en Venezuela (desde la Colonia al siglo XIX). Universidad de Venezuela-Fondo Editorial Tropikos, Caracas.

Pińa, C. 1986. "Sobre las historias de vida y su campo de validez en las ciencias sociales", Documento de trabajo 319, pp:1-41. FLACSO, Santiago de Chile.

Podestá, M. M. y D. Rolandi. 2000. "Sobre dinosaurios y marcas de ganado. Prospección arqueológica en Ischigualasto”. Novedades de Antropología. Boletin Informativo del INAPL 37: 3-6. 
Podestá, M. M. y D. Rolandi. 2001. "Marcas en el Desierto. Arrieros en Ischigualasto". Boletin de la Sociedad de Investigación del Arte Rupestre de Bolivia 15: 63-73.

Podestá, M. M, D. Rolandi, A. Re, M. P. Falchi y O. Damiani. 2006. "Arrieros y marcas de ganado: expresiones de arte rupestre de momentos históricos en el desierto de Ischigualasto". En: Tramas en la Piedra. Producción y Usos del Arte Rupestre editado por Danae Fiore y María Mercedes Podestá, pp. 169-190. WAC, SAA y AINA, Buenos Aires.

Politis, G. 2003. "The theoretical landscape and the methodological development in América Latina”. American Antiquity 68 (2): 245-272.

Politis, G. 2006a. "El paisaje teórico y el desarrollo metodológico de la Arqueología en América Latina”. Arqueología Sudamericana 2 (2): 168-174.

Politis, G. 2006b. "Réplica. Más sobre los paisajes teóricos de America Latina. Una respuesta con bastantes acuerdos, ciertos desacuerdos y algunas reflexiones tardías". Arqueología Sudamericana 2 (2): 192-199.

Prieto, R. 1992. “Geoglifos del río Jachal, Provincia de San Juan”. Publicaciones 19: 2-6.

Riveros, M. G. 2004. "Los conceptos de "campo expandido" y "color" en el análisis de petroglifos". Publicaciones 26 (nueva serie): 51-58.

Riveros, M. G. y A. Varela. 2001. "Ischigualasto: estudio preliminar del arte rupestre”. Publicaciones 25: 131-147.

Sachero, P. 1976. "Prospección arqueológica en el valle del río Blanco-Jáchal (Provincia de San Juan)". Anales de Arqueología y Etnología XXIX-XXXI: 37-66.

Sanoja, M y I. Vargas. 1995. "La arqueología como ciencia social y su expresión en América Latina”. Arqueología americana 9: 141-163.

Schobinguer, J. 1962. "Investigaciones arqueológicas en la provincia de San Juan, Argentina (informe preliminar)”. Actas del XXXV Congreso Internacional de Americanistas 1: 615-617. México.

Schobinguer, J. 1966. La "Momia" del Cerro El Toro. Suplemento del Tomo XXI de Anales de Arqueología y Etnología, Mendoza.

Stagnaro, A. 1993. "La Antropología en la comunidad científica: entre el origen del hombre y la caza de cráneos-trofeo (1870-1910)". Alteridades 3 (6):5365.

Vignati, M. 1934. El ajuar de una momia de Angualasto. Buenos Aires, Universidad Nacional de La Plata, La Plata. 